\title{
Evaluation of Smile Parameters in Nongrowing Subjects Using Photographs
}

\author{
Mandeep Bhullar ${ }^{1}$ Yagyeshwar Malhotra ${ }^{1} \quad$ Sanjay Mittal ${ }^{1} \quad$ Isha Aggarwal ${ }^{1} \quad$ Divya Singla $^{1} \quad$ Merry Goyal $^{1}$ \\ ${ }^{1}$ Department of Orthodontics and Dentofacial Orthopedics, Bhojia \\ Address for correspondence Yagyeshwar Malhotra, Department of \\ Dental College, Baddi, Himachal Pradesh, India \\ Orthodontics and Dentofacial Orthopedics, Bhojia Dental College, Baddi, \\ Himachal Pradesh 173205, India (e-mail: y9417804155@gmail.com).
}

Dent J Adv Stud 2019;7:87-94

\begin{abstract}
Introduction An attractive or pleasing smile enhances the acceptance of an individual in the society by improving interpersonal relationships. In this new era of social media, people are more concerned about their smile; hence, smile esthetics has become the primary objective of orthodontic treatment. It is seen that various smile parameters change with age and gender.

Aim The aim of the study was to evaluate various smile parameters in nongrowing patients using photographic analysis.

Materials and Methods The sample comprised photographs of 50 subjects ( 8 males, 42 females) taken in natural head position and then divided into two age groups: Group I ( 25 subjects, aged $18-20$ years) and Group II ( 25 subjects, aged $23-29$ years). The various parameters were analyzed using Adobe Photoshop software (version CS 6; Adobe System Inc., California, United States): upper lip and lower lip lengths during rest and smiling, smile index, buccal corridor, upper and lower lip thickness, interlabial gap, incisal display, widest visible maxillary display, and intercommissural width.

Results The results showed that lower lip length at rest and smiling, interlabial gap, incisal display, inner commissure width, and widest visible maxillary display were increased, whereas upper lip length both at rest and smiling, upper and lower lip thickness, outer commissure width, smile index, and buccal corridor were decreased with

Keywords

- smile parameters

- esthetics

- buccal corridor age. Statistically significant sex-related differences were found in upper lip length at rest and lower lip length both at rest and smiling.

Conclusion Orthodontic treatment must incorporate various esthetic elements of smile to achieve desirable results.
\end{abstract}

\section{Introduction}

Smile is one of the most important expressions contributing to facial attractiveness. "Smile" as defined by Merriam-Webster is "a change of facial expression involving a brightening of the eyes, an upward curving of the corners of the mouth with no sound and less muscular distortion of the features than in a laugh that may express amusement, pleasure, tender, affection, approval, restrained mirth, irony, derision or any of the other various emotions." ${ }^{1,2}$

Interpersonal relationships are improved by an attractive or pleasing smile as it enhances the acceptance of an

received

July 24, 2019

accepted

July 30, 2019

published online

October 18, 2019 individual in the society. ${ }^{3}$ With patients becoming increasingly conscious of a beautiful smile, smile esthetics has become the primary objective of orthodontic treatment. ${ }^{4}{ }^{45}$ Modern orthodontics deals not only with the traditional dental and skeletal aspects, but also with face as the first priority. To achieve a balanced smile is the most important esthetic goal in orthodontics, which can be best described as an appropriate positioning of teeth and gingival scaffold within the dynamic display zone. - $^{6}$

Therefore, this study was done to evaluate the parameters related to upper lip length at rest and during smiling, lower lip length at rest and during smiling, upper lip thickness,

\section{License terms}

()(1) $\ominus \circledast$ 
lower lip thickness, maxillary incisal display, interlabial gap at smile, smile index, buccal corridors, widest visible maxillary display and intercommissural width, sexual dimorphism with respect to smile, and age-related changes of the smile.

\section{Aims and Objectives}

The aims and objectives of the study are to evaluate smile parameters in nongrowing patients using photographs.

\section{Materials and Methods}

This study was conducted in the Department of Orthodontics, Bhojia Dental College, Baddi, Himachal Pradesh, India. The sample consisted of male and female adults reporting to the department. The details of the study were explained to the potential subjects.

The inclusion criteria for selection were as follows:

1. Class I subjects with well-balanced faces/orthognathic profile

2. No previous orthodontic treatment or maxillofacial surgery

3. Complete permanent dentition

4. Voluntary involvement in the study

5. No active periodontal disease

6. No craniofacial anomalies or other pathologies

7. No severe malocclusion

8. No deleterious habit causing malocclusion (tongue thrusting, thumb-sucking, etc.)

The exclusion criteria were as follows:

1. Missing teeth that could have been visible on smile

2. Prosthodontic work on teeth visible in smile

3. Excessive dental attrition

4. Lip irregularities (incompetent, potentially incompetent, short lips, etc.)

5. Inability to determine natural head position

Depending upon these criteria, 50 subjects comprising 8 males and 42 females with age ranging from 18 to 29 years were selected. All the photographs were taken in natural head position in which the patient head was in an upright posture with the eyes focused on a point in the distance at eye level, which signifies that the visual axis is horizontal. The photographs taken for each subject will follow the described standardized parameters:

1. Nikon D-3300 digital camera was used for taking photographs for all the subjects.

2. Distance between the camera and the subject was taken as $3.5 \mathrm{ft}$.

3. The camera was mounted on a tripod stand with the lens positioned parallel to the true perpendicular of the face in natural head position.

4. The camera was raised to the level of subject's lower facial third.

5. Illumination was kept same for photography of each individual.
Each file was opened in Adobe Photoshop software and adjusted so as to get 1:1 ratio. To check the accuracy of these steps, the $10-\mathrm{mm}$ area on the ruler was measured again. If done precisely, this measurement would read $10 \mathrm{~mm}$ and thus direct measurements could be recorded.

The various parameters studied for all the subjects using Adobe Photoshop software were as follows (-Figs. 1 and 2):

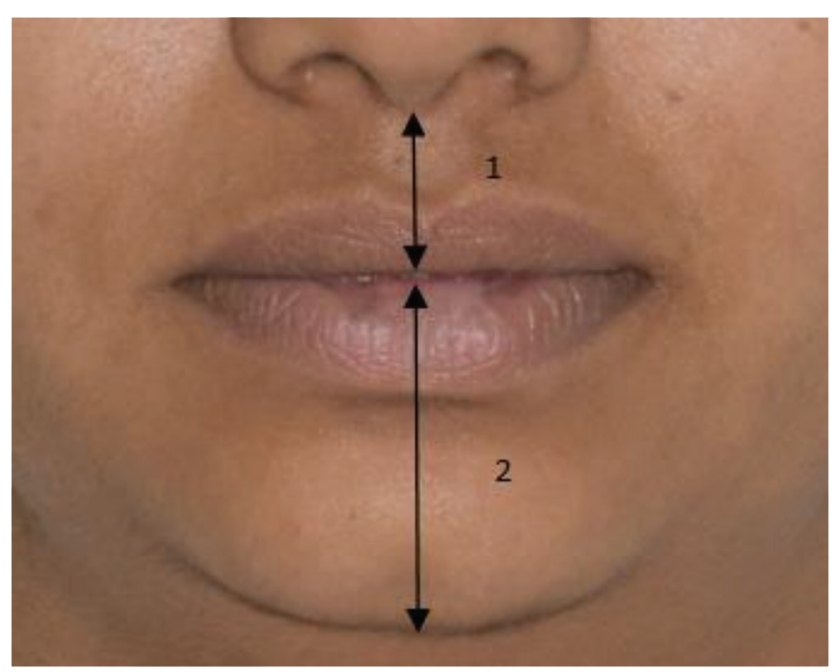

Fig. 1 (1) Upper lip length at rest and (2) lower lip length at rest.

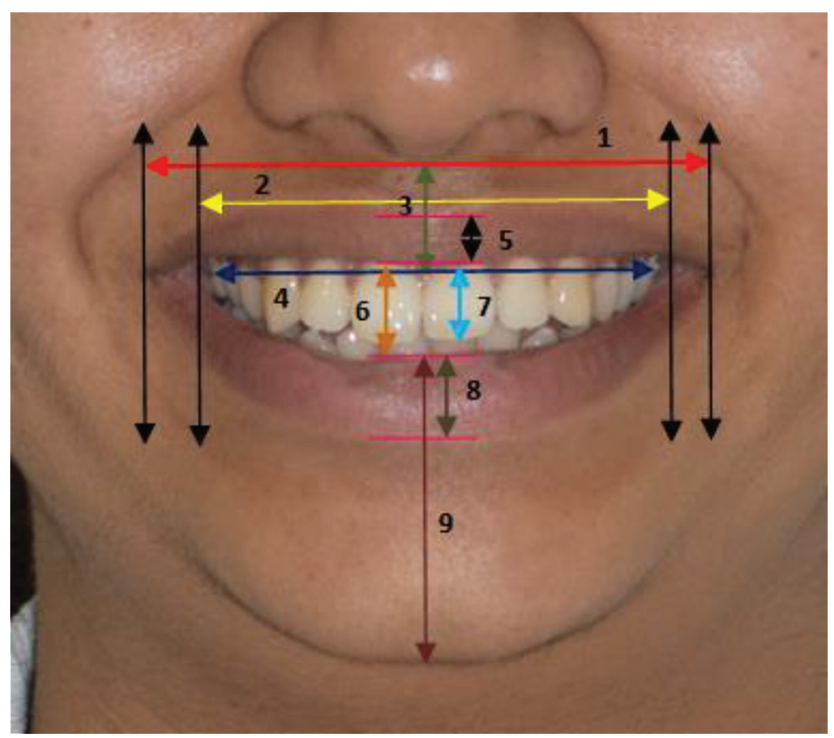

Fig. 2 (1) Outer commissure width-distance from outer most corner of the mouth from one side to the other, (2) inner commissure width-distance from inner most corner of the mouth from one side to the other, (3) upper lip length (smiling)-from subnasale to stomion superius, (4) visible maxillary widest display-teeth displayed from first molar to first molar, (5) upper lip thickness-vertical distance from the most superior point of the cupid's bow to the most inferior portion of the tubercle of the upper lip, (6) interlabial gap-the position of the upper and lower lips as measured from the midpoint of the lips when a patient is relaxed and smiling, (7) incisal display-stomion superius to maxillary incisor edge (if the central incisors were not at the same levels, two measurements were taken and the average was used for that subject), (8) lower lip thickness-lower lip inside to vermilion-cutaneous junction, and (9) lower lip length (smiling)-from stomion inferius to menton. 
(1) Upper lip length at rest and during smiling-subnasale to stomion superius; (2) lower lip length at rest and during smiling-from stomion inferius to menton; (3) upper lip thickness-vertical distance from the most superior point of the cupid's bow to the most inferior portion of the tubercle of the upper lip; (4) lower lip thickness-lower lip inside to vermilion-cutaneous junction; (5) maxillary incisor display-stomion superius to maxillary incisor edge (if the central incisors were not at the same levels, two measurements were taken and the average was used for that subject); (6) interlabial gap at smile-the position of the upper and lower lips as measured from the midpoint of the lips when a patient was relaxed and smiling; (7) outer intercommissural width-distance from outer most corner of the mouth from one side to the other; (8) inner intercommissural width; (9) visible maxillary dental width; (10) smile index was determined by dividing the outer intercommissural width by the interlabial gap height during smile $^{9}$; and (11) buccal corridor represented by a ratio of the intercommissural width divided by the distance from the first premolar to first premolar. It attributes to the dark space (negative space) visible during smile formation between the corners of the mouth and the buccal surfaces of the maxillary teeth and is measured from the mesial line angle of the maxillary first premolar to the interior portion of the commissure of lips.,10,11 The smile parameters were compared between males and females for any gender differentiation.

The subjects were further divided into two groups, depending upon age ( - Table 1 ), that is, Group I (18-20 years) and Group II (23-29 years). All the parameters were compared

Table 1 Description of study sample (age group)

\begin{tabular}{|l|l|l|}
\hline Groups & Age, years & Total \\
\hline Group I & $18-20$ & 25 \\
\hline Group II & $23-29$ & 25 \\
\hline Total & & 50 \\
\hline
\end{tabular}

for these two groups to check for any variation within this age range.

\section{Statistical Analysis}

The data obtained were subjected to statistical analysis using SPSS version (IBM Corp., New York, United States) and to check for normality by using Skewness and Kurtosis test and were found to be normally distributed.

The values obtained were compiled, mean and standard deviation were calculated, and paired $t$ test was applied to analyze the mean values of various smile parameters for any sexual dimorphism and to compare the two groups differed by age.

\section{Results}

The values obtained for various smile parameters were compiled, and mean and standard deviation were calculated (-Table 2).

The smile parameters evaluated were compared for the male and female subjects. The results showed statistically significant sex-related differences in upper lip length at rest and lower lip length both at rest and smiling (-Table 3; -Fig. 3).

The parameters evaluated for smile were compared for the subjects divided into two groups (Group I: 18-20 years, Group II: 23-29 years) depending upon the age. The results showed no statistically significant difference among the two age-related groups under investigation (-Table 4; —Fig. 4).

\section{Discussion}

Improvement in facial esthetics is nowadays considered as a paramount objective in modern orthodontics. An orthodontist uses various measurements of facial features to evaluate soft tissue form and relationships, which ultimately help him form

Table 2 Overall mean value of parameters

\begin{tabular}{|l|l|l|l|l|}
\hline Parameters & Sample & Mean & Standard deviation & Standard error \\
\hline Upper lip length at rest & 50 & 22.45 & 0.085 & 0.31 \\
\hline Lower lip length at rest & 50 & 50.8 & 0.215 & 0.77 \\
\hline Upper lip length during smiling & 50 & 17.02 & 0.100 & 0.36 \\
\hline Lower lip length during smiling & 50 & 49.17 & 0.223 & 0.80 \\
\hline Upper lip thickness & 50 & 6.37 & 0.073 & 0.26 \\
\hline Lower lip thickness & 50 & 10.33 & 0.077 & 0.28 \\
\hline Interlabial gap & 50 & 10.59 & 0.125 & 0.45 \\
\hline Incisal display & 50 & 9.32 & 0.108 & 0.39 \\
\hline Outer commissure width & 50 & 76.96 & 0.264 & 0.95 \\
\hline Inner commissure width & 50 & 64.41 & 0.183 & 0.66 \\
\hline Widest visible maxillary display & 50 & 61.54 & 0.174 & 0.63 \\
\hline Smile index & 50 & 8.161 & 3.828 & 0.37 \\
\hline Buccal corridor & 50 & 1.416 & 0.112 & 0.02 \\
\hline
\end{tabular}


Table 3 Mean value of parameters according to sex (t-test)

\begin{tabular}{|c|c|c|c|c|c|c|c|}
\hline Parameters & Sex & $n$ & Mean & $\begin{array}{l}\text { Standard } \\
\text { deviation }\end{array}$ & $\begin{array}{l}\text { Standard } \\
\text { error mean }\end{array}$ & $t$-Value & $p$-Value \\
\hline \multirow[t]{2}{*}{ Upper lip length at rest } & Male & 8 & 23.90 & 2.27 & 0.80 & 2.132 & $0.038^{\mathrm{a}}$ \\
\hline & Female & 42 & 22.18 & 2.06 & 0.32 & & \\
\hline \multirow[t]{2}{*}{ Lower lip length at rest } & Male & 8 & 57.84 & 5.55 & 1.96 & 4.801 & $0.0001^{b}$ \\
\hline & Female & 42 & 49.45 & 4.34 & 0.67 & & \\
\hline \multirow[t]{2}{*}{ Upper lip length during smiling } & Male & 8 & 18.61 & 2.88 & 1.02 & 1.915 & 0.061 \\
\hline & Female & 42 & 16.78 & 2.39 & 0.37 & & \\
\hline \multirow[t]{2}{*}{ Lower lip length during smiling } & Male & 8 & 57.47 & 6.10 & 2.16 & 5.856 & $0.0001^{\mathrm{b}}$ \\
\hline & Female & 42 & 47.61 & 4.00 & 0.62 & & \\
\hline \multirow[t]{2}{*}{ Upper lip thickness } & Male & 8 & 6.71 & 2.95 & 1.04 & 0.573 & 0.570 \\
\hline & Female & 42 & 6.30 & 1.60 & 0.25 & & \\
\hline \multirow[t]{2}{*}{ Lower lip thickness } & Male & 8 & 11.40 & 2.14 & 0.76 & 1.708 & 0.094 \\
\hline & Female & 42 & 10.13 & 1.88 & 0.29 & & \\
\hline \multirow[t]{2}{*}{ Inter labial gap } & Male & 8 & 10.12 & 2.46 & 0.87 & -0.460 & 0.647 \\
\hline & Female & 42 & 10.69 & 3.30 & 0.51 & & \\
\hline \multirow[t]{2}{*}{ Incisal display } & Male & 8 & 7.83 & 1.85 & 0.65 & -1.686 & 0.098 \\
\hline & Female & 42 & 9.59 & 2.82 & 0.44 & & \\
\hline \multirow[t]{2}{*}{ Outer commissure width } & Male & 8 & 79.84 & 6.52 & 2.30 & 1.344 & 0.185 \\
\hline & Female & 42 & 76.40 & 6.67 & 1.03 & & \\
\hline \multirow[t]{2}{*}{ Inner commissure width } & Male & 8 & 66.11 & 4.73 & 1.67 & 1.133 & 0.263 \\
\hline & Female & 42 & 64.09 & 4.61 & 0.71 & & \\
\hline \multirow[t]{2}{*}{ Widest visible maxillary display } & Male & 8 & 62.36 & 5.19 & 1.84 & 0.560 & 0.578 \\
\hline & Female & 42 & 61.39 & 4.32 & 0.67 & & \\
\hline \multirow[t]{2}{*}{ Smile index } & Male & 8 & 8.41 & 2.62 & 0.93 & 0.645 & 0.522 \\
\hline & Female & 42 & 7.76 & 2.61 & 0.40 & & \\
\hline \multirow[t]{2}{*}{ Buccal corridor } & Male & 8 & 1.45 & 0.15 & 0.05 & 0.908 & 0.368 \\
\hline & Female & 42 & 1.41 & 0.10 & 0.02 & & \\
\hline
\end{tabular}

aSignificant.

'Highly significant.

diagnosis and treatment therapy to achieve facial attractiveness. ${ }^{12}$ Furthermore, attractiveness is suggested to influence personality development and social interaction. ${ }^{13}$ Smile also influences a person's perceived attractiveness and is the cornerstone of social interaction..$^{14}$ Hence, the aim of this study was to evaluate various parameters that can influence the smile. The significant parameters of the smile are as follows.

\section{Upper Lip Length}

The mean value for all subjects for upper lip length at rest in this study was $22.45 \pm 0.085 \mathrm{~mm}$. Similar findings were observed by Desai et al ${ }^{15}$ and Arnett and Bergman ${ }^{16}$ with lip length as $21.96 \pm 2.27$ and 19 to $22 \mathrm{~mm}$, respectively. This study showed mean value for all subjects for upper lip length during smiling as $17.02 \pm 0.10 \mathrm{~mm}$.

This study showed upper lip length at rest to be $23.9 \pm$ $2.2 \mathrm{~mm}$ for males and $22.18 \pm 2 \mathrm{~mm}$ for females. The difference was statistically significant, showing increased mean values for male subjects. Similar findings were reported by Farkas et a $\mathrm{l}^{17}$ and Wolford. ${ }^{18}$

A decrease in upper lip length at rest from $22.6 \pm 2.3 \mathrm{~mm}$ (Group I) to $22.1 \pm 1.9 \mathrm{~mm}$ (Group II) was observed, although it was statistically nonsignificant. The results are in accordance with the study conducted by Desai et al. ${ }^{15}$ Similarly upper lip length during smiling also decreased from $17.6 \pm 2.9$ $\mathrm{mm}$ (Group I) to $16.5 \pm 1.8 \mathrm{~mm}$ (Group II) (nonsignificant), indicating atrophy of muscles with advancing age leading to a decrease in lip volume, loss of lip architecture, and lip lengthening. These changes act as a reference for older age subjects while rendering them orthodontic treatment.

\section{Lower Lip Length}

The mean value for complete sample for lower lip length at rest for this sample was $50.8 \pm 0.22 \mathrm{~mm}$. However, the mean value for lower lip length during smiling was $49.17 \pm 0.22 \mathrm{~mm}$. 


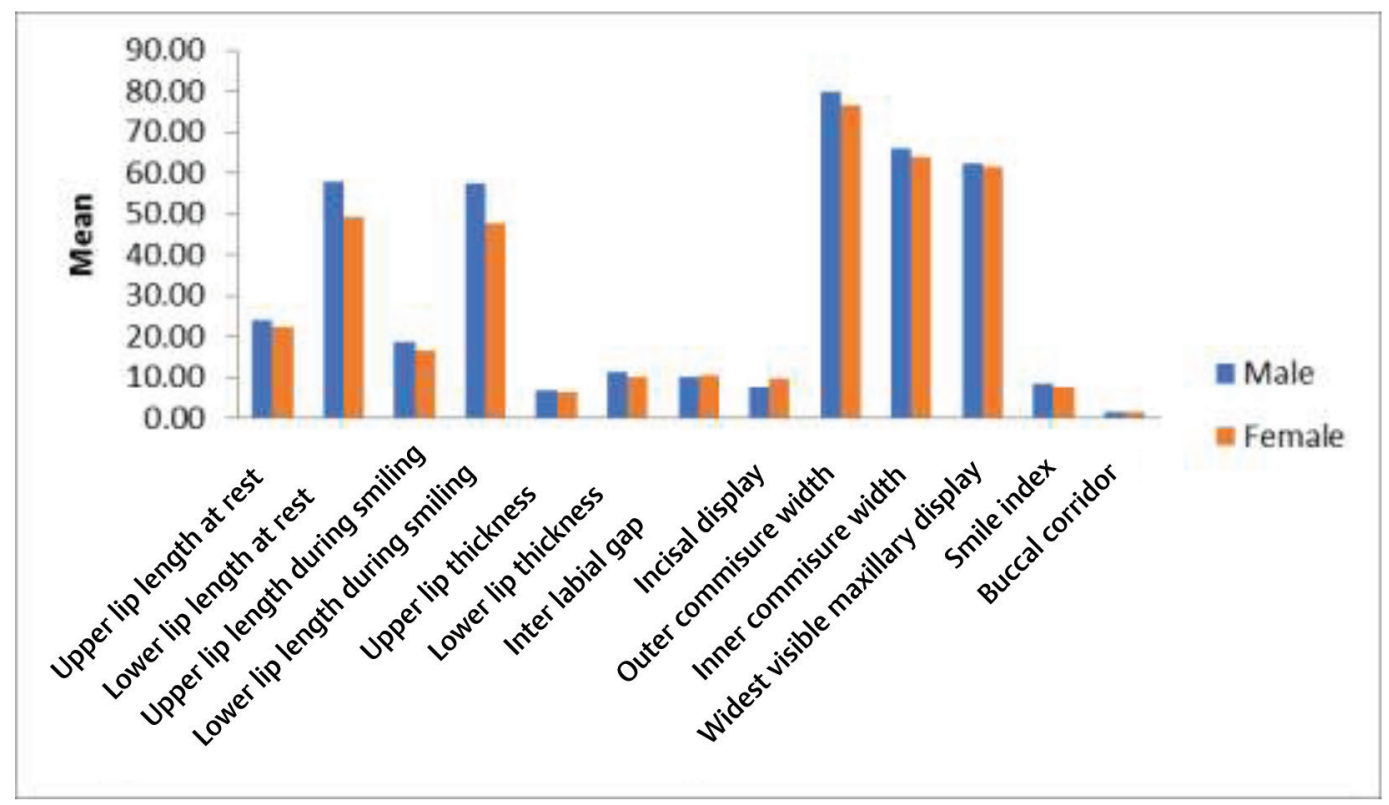

Fig. 3 Mean values of parameters according to sex.

Table 4 Mean value of parameters according to age ( $t$-test)

\begin{tabular}{|c|c|c|c|c|c|c|c|}
\hline Parameters & Groups & $N$ & Mean & $\begin{array}{l}\text { Standard } \\
\text { deviation }\end{array}$ & $\begin{array}{l}\text { Standard } \\
\text { error mean }\end{array}$ & $t$-Value & $p$-Value \\
\hline \multirow[t]{2}{*}{ Upper lip length at rest } & Group I & 25 & 22.69 & 2.39 & 0.48 & 0.740 & 0.463 \\
\hline & Group II & 25 & 22.23 & 1.94 & 0.39 & & \\
\hline \multirow[t]{2}{*}{ Lower lip length at rest } & Group I & 25 & 49.83 & 4.74 & 0.95 & 1.249 & 0.218 \\
\hline & Group II & 25 & 51.75 & 6.03 & 1.21 & & \\
\hline \multirow[t]{2}{*}{ Upper lip length during smiling } & Group I & 25 & 17.64 & 2.99 & 0.60 & 1.599 & 0.116 \\
\hline & Group II & 25 & 16.51 & 1.87 & 0.37 & & \\
\hline \multirow[t]{2}{*}{ Lower lip length during smiling } & Group I & 25 & 47.88 & 4.95 & 0.99 & 1.660 & 0.104 \\
\hline & Group II & 25 & 50.49 & 6.11 & 1.22 & & \\
\hline \multirow[t]{2}{*}{ Upper lip thickness } & Group I & 25 & 6.74 & 1.93 & 0.39 & 1.475 & 0.147 \\
\hline & Group II & 25 & 5.98 & 1.71 & 0.34 & & \\
\hline \multirow[t]{2}{*}{ Lower lip thickness } & Group I & 25 & 10.62 & 1.85 & 0.37 & 1.045 & 0.301 \\
\hline & Group II & 25 & 10.04 & 2.06 & 0.41 & & \\
\hline \multirow[t]{2}{*}{ Inter labial gap } & Group I & 25 & 10.40 & 3.08 & 0.62 & 0.448 & 0.656 \\
\hline & Group II & 25 & 10.80 & 3.31 & 0.66 & & \\
\hline \multirow[t]{2}{*}{ Incisal display } & Group I & 25 & 8.89 & 2.41 & 0.48 & 1.075 & 0.288 \\
\hline & Group II & 25 & 9.73 & 3.06 & 0.61 & & \\
\hline \multirow[t]{2}{*}{ Outer commissure width } & Group I & 25 & 77.08 & 6.18 & 1.24 & 0.138 & 0.890 \\
\hline & Group II & 25 & 76.82 & 7.31 & 1.46 & & \\
\hline \multirow[t]{2}{*}{ Inner commissure width } & Group I & 25 & 63.65 & 3.88 & 0.78 & 1.163 & 0.251 \\
\hline & Group II & 25 & 65.17 & 5.26 & 1.05 & & \\
\hline \multirow[t]{2}{*}{ Widest visible maxillary display } & Group I & 25 & 60.52 & 3.91 & 0.78 & 1.665 & 0.103 \\
\hline & Group II & 25 & 62.57 & 4.74 & 0.95 & & \\
\hline \multirow[t]{2}{*}{ Smile index } & Group I & 25 & 7.97 & 2.79 & 0.56 & 0.299 & 0.766 \\
\hline & Group II & 25 & 7.75 & 2.43 & 0.49 & & \\
\hline \multirow[t]{2}{*}{ Buccal corridor } & Group I & 25 & 1.43 & 0.11 & 0.02 & 0.875 & 0.386 \\
\hline & Group II & 25 & 1.40 & 0.11 & 0.02 & & \\
\hline
\end{tabular}




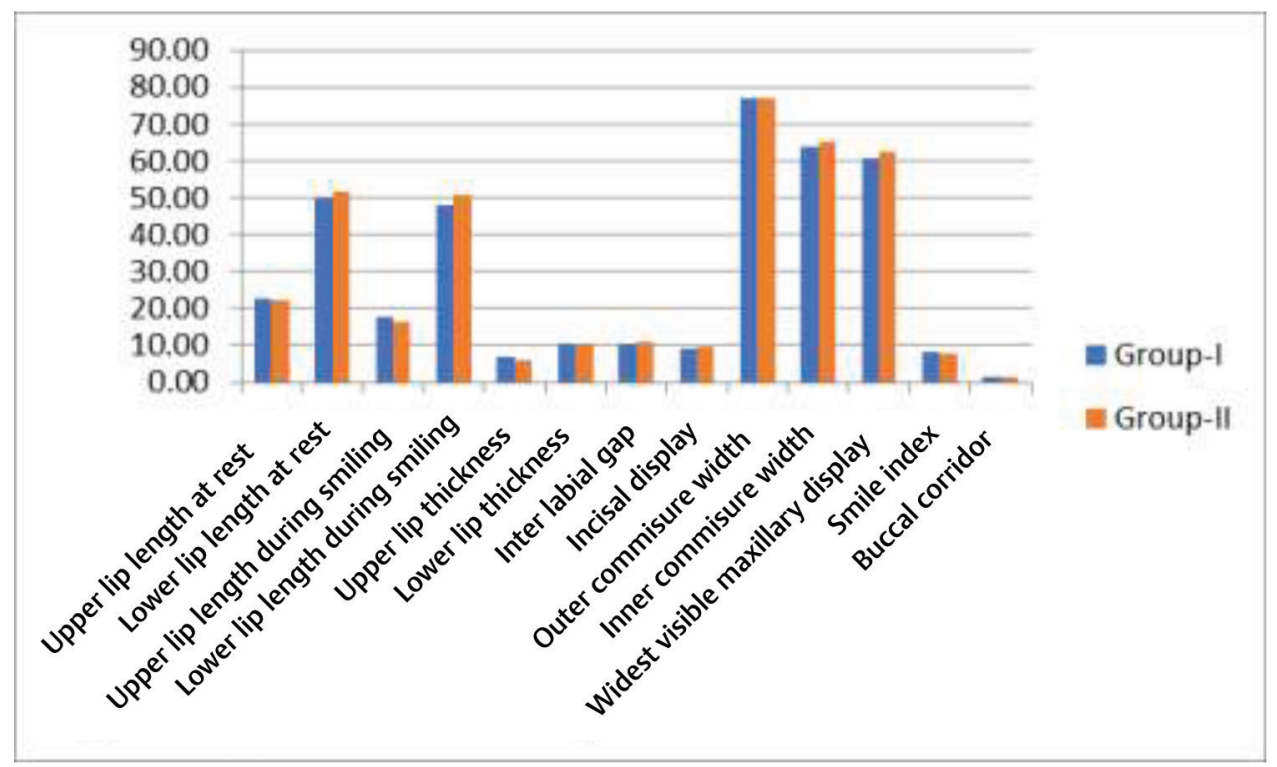

Fig. 4 Mean values of parameters according to age.

For males and females, the lower lip length at rest was found out to be $57.8 \pm 5.5$ and $49.44 \pm 4.3 \mathrm{~mm}$, respectively, and during smiling it is $57.4 \pm 6.1$ and $47.6 \pm 4 \mathrm{~mm}$ for male and female subjects, respectively. Both these values showed statistically significant difference between genders. So, it can be interpreted that the mean values were higher for males than females and it is in accordance with the study conducted by Scheideman et al. ${ }^{19}$

There was an increase in lower lip length at rest from $49.8 \pm$ 6 to $51.7 \pm 4.7 \mathrm{~mm}$ and during smiling from $47.8 \pm 4.9$ to $50.4 \pm$ $6.1 \mathrm{~mm}$ when compared for Group I and Group II, respectively.

\section{Upper Lip Thickness}

The mean value for the complete sample for upper lip thickness was $6.37 \pm 0.07 \mathrm{~mm}$, whereas, according to a study conducted by Schabel et al, ${ }^{20}$ the mean value for upper lip thickness is found to be $7.4 \pm 1.8 \mathrm{~mm}$.

This study showed upper lip thickness of $6.7 \pm 2.9 \mathrm{~mm}$ for males and $6.3 \pm 1.6 \mathrm{~mm}$ for females. Similar results were obtained by the study conducted by Chetan et al. ${ }^{21}$

There was a decrease of upper lip thickness with age, from $6.7 \pm 1.9 \mathrm{~mm}$ (Group I) to $5.9 \pm 1.7 \mathrm{~mm}$ (Group II), although it was statistically nonsignificant and can be attributed to an empirical observation of thinning of lips with age. This was in accordance with the observations found in the study conducted by Chetan et al, ${ }^{21}$ which showed a decrease in upper lip thickness with age.

\section{Lower Lip Thickness}

This study showed overall mean value for lower lip thickness to be $10.33 \pm 0.07 \mathrm{~mm}$. Similar findings were reported by Schabel et $\mathrm{a}^{20}$ with a mean lower lip thickness value of $10.1 \pm 1.8 \mathrm{~mm}$.

This study showed higher mean value of lower lip thickness for males $11.4 \pm 2.1 \mathrm{~mm}$ as compared with females $10.1 \pm 1.8 \mathrm{~mm}$, which is in accordance with the findings reported by Kalha et $\mathrm{a}^{22}$ and Arnet and Bergman, ${ }^{16}$ showing a higher value for males as compared with females.
There was a slight decrease in mean values of lower lip thickness from $10.6 \pm 1.8 \mathrm{~mm}$ (Group I) to $10 \pm 2 \mathrm{~mm}$ (Group II), although it was not statistically significant.

\section{Interlabial Gap}

The overall mean value for interlabial gap was found to be $10.59 \pm 0.13 \mathrm{~mm}$. Similar findings were reported by Schabel et $\mathrm{al}^{20}$ with a mean value for interlabial gap as $11.9 \pm 2.9 \mathrm{~mm}$.

This study showed mean values for interlabial gap for males to be $10.1 \pm 2.4 \mathrm{~mm}$ and for females to be $10.6 \pm 3.3$ $\mathrm{mm}$, although it was nonsignificant. Similar results were reported by a study conducted by Sachdeva et al. ${ }^{23}$

The data showed an increase in interlabial gap from $10.3 \pm 3 \mathrm{~mm}$ (Group I) to $10.8 \pm 3.3 \mathrm{~mm}$ (Group II), which can be due to reduced upper lip thickness/thinning of upper lip, although it was nonsignificant. The results were in contrast to those in the study done by Sachdeva et $\mathrm{al}^{23}$ and Desai et al, ${ }^{15}$ who reported a decrease in interlabial gap with age from 12 to $10.42 \mathrm{~mm}$, suggesting that as the person ages, the smile gets wider transversely and narrower vertically.

\section{Incisal Display}

The overall mean for incisal display was $9.32 \pm 0.10 \mathrm{~mm}$. Similarly, according to Schabel et al, ${ }^{20}$ the mean value for incisal display reported was $8.5 \pm 1.5 \mathrm{~mm}$.

This study showed no statistically significant differences in incisal display with respect to gender, $7.8 \pm 1.8 \mathrm{~mm}$ for males and $9.5 \pm 2.8 \mathrm{~mm}$ for females. Similar results were obtained during a study conducted by Sachdeva et al. ${ }^{23}$

The data showed an increase in incisal display from $8.8 \pm 2.4 \mathrm{~mm}$ (Group I) to $9.7 \pm 3 \mathrm{~mm}$ (Group II), although it was not statistically significant and can be attributed to increased interlabial gap or reduced upper lip thickness. As the mean age for Group II is 25 years and for Group I it is 19 years, so the chances of attrition of anterior teeth are also low at this young age, which in turn contributes to an increase in incisal display. However, results in contrast were obtained 
in the studies conducted by Hulsey, ${ }^{2}$ Tjan et al, ${ }^{3}$ and Sachdeva et $\mathrm{al}^{23}$ showing a decrease in upper incisal display on smiling with age. According to Dickens et al, ${ }^{24}$ who studied incisal display both at rest and during smile, it can be predicted that incisor display will decrease with age. Therefore, leaving the incisors somewhat more prominent than the ideal for early adolescence, can provide better esthetic later.

\section{Outer Commissure Width}

Overall mean value for outer commissure width as per this study was $76.96 \pm 0.26 \mathrm{~mm}$. Similarly, a study conducted by Schabel et $\mathrm{al}^{20}$ showed the mean value for outer commissure width as $60 \pm 5 \mathrm{~mm}$.

This study showed statistically nonsignificant differences in the values for outer commissure width for males as $79.8 \pm 6.5 \mathrm{~mm}$ and females as $76.4 \pm 6.6 \mathrm{~mm}$. This finding was found to be in accordance with study conducted by Chetan et al..$^{21}$

Outer commissure width is decreased with age from $77 \pm 6.1 \mathrm{~mm}$ (Group I) to $76.8 \pm 7.3 \mathrm{~mm}$ (Group II), although it is statistically nonsignificant. This slight decrease in outer commissure width indicates a decrease in horizontal component of smile.

\section{Inner Commissure Width}

The overall mean value for inner commissure width for complete sample for this study was $64.41 \pm 0.18 \mathrm{~mm}$.

This study showed mean values for inner commissure width for males as $66.1 \pm 4.7 \mathrm{~mm}$ and for females as $64 \pm$ $4.6 \mathrm{~mm}$, although it was found to be nonsignificant. Similar results were reported by Sachdeva et al. ${ }^{23}$

There was an increase in inner commissure width with age from $63.6 \pm 3.8 \mathrm{~mm}$ (Group I) to $65.1 \pm 5.2 \mathrm{~mm}$ (Group II), although it was not statistically significant. These results are in accordance with the study conducted by Sachdeva et al. ${ }^{23}$

\section{Smile Index}

The overall mean value for smile index for this study was 8.16 $\pm 3.8 \mathrm{~mm}$, whereas according to studies conducted by Ackerman et al, ${ }^{9}$ the mean value for smile index was $5.3 \pm 1.46 \mathrm{~mm}$. Similarly, Schabel et al ${ }^{20}$ also found the mean value for smile index to be $5.3 \pm 1.6 \mathrm{~mm}$.

This study showed nonsignificant mean values for smile index, for males as $8.4 \pm 2.6 \mathrm{~mm}$ and for females as $7.7 \pm 2.6 \mathrm{~mm}$.

This study showed reduction in smile index with age from $8.5 \pm 2.7$ (Group I) to $7.7 \pm 2.4$ (Group II), which can be attributed to an increase in interlabial gap although the results were statistically nonsignificant. These results were contrary to the study conducted by Sachdeva et $\mathrm{al}^{23}$ and Sarver and Ackerman, ${ }^{25}$ reporting an increase in smile index with age.

\section{Buccal Corridor}

The overall mean value for buccal corridor in this study was $1.4 \pm 0.11 \mathrm{~mm}$. However, according to Ackerman et $\mathrm{al}^{9}{ }^{9}$ the mean value for buccal corridor was $0.6 \pm 0.5 \mathrm{~mm}$ and according to Schabel et al ${ }^{20}$ it was $0.8 \pm 0 \mathrm{~mm}$.

However, it showed nonsignificant differences among males $(1.45 \pm 0.15) \mathrm{mm}$ and among females $(1.41 \pm 0.10) \mathrm{mm}$.
The results of our study, which looked at differences between buccal corridor spaces, indicated no statistically significant difference in either sex and age groups. This is in accordance with the study conducted by Martin et al. ${ }^{26}$ Thus, we can assume that buccal corridor space plays only a minimal role in esthetic evaluation of a smile and the perceived difference could be due to other factors such as smile arc, tooth arrangement, tooth shade, gingival architecture, gingival display, and lip thickness. It also helps to broaden our knowledge and understanding of how the perioral soft tissues change with age and helps clinicians optimize dentofacial esthetics while satisfying other treatment goals.

The data showed a decrease in buccal corridor with age from $1.43 \pm 0.11$ (Group I) to $1.40 \pm 0.11$ (Group II), although it was not statistically significant.

\section{Conclusion}

The study was conducted on 50 nongrowing subjects to study smile parameters. The sample was studied to evaluate any gender differentiation for various smile parameters. Standardized photographs were taken with a posed smile. The sample was further divided into two groups according to age difference (Group I from 18 to 20 years and Group II from 23 to 29 years) and the changes in smile parameters were studied between the two groups. These results showed the following:

1. The values for various smile parameters were evaluated for the nongrowing subjects.

2. Statistically significant difference was obtained among male and female subjects in three parameters-upper lip length at rest, lower lip length at rest, and lower lip length during smiling, indicating that males had larger upper lip length at rest and lower lip length both at rest and smiling to be larger than the females.

3. No statistically significant difference was found between the two groups and the reason can be attributed to small difference in mean age among the two sample groups (19 years and 25 years). The sample consisted of young subjects, which showed little change in muscle tonicity.

As we know that time has been incorporated as the fourth dimension in the treatment planning, knowledge of changes in dentofacial structures has become paramount to achieve successful orthodontic treatment. ${ }^{27}$ With the passage of time, people undergo many skeletal and soft tissue cellular changes that dramatically affect the overlying soft tissue envelope. Appropriate knowledge of the smile characteristic at any stage and smile changes with sexual dimorphism and with age can help orthodontists obtain long-lasting and esthetically appealing treatment results.

\section{Note}

This study was conducted at Bhojia Dental College and Hospital, Baddi, Himachal Pradesh, India.

\section{Conflict of Interest}

None declared. 


\section{References}

1 Grove, Philip B. Webster's third new international dictionary of the English language (Vol. II). 14th ed. Springfield, United States: G \& C Merriam Company;2151

2 Hulsey CM. An esthetic evaluation of lip-teeth relationships present in the smile. Am J Orthod 1970;57(2):132-144

3 Tjan AH, Miller GD, The JG. Some esthetic factors in a smile. J Prosthet Dent 1984;51(1):24-28

4 Springer N C, Chan C, Fields H W, et al. Smile esthetics from the layperson's perspective. Am J Orthod Dentofacial Orthop 2011;139:e91-e101

5 Sharma PK, Sharma P. Dental smile esthetics: the assessment and creation of the ideal smile. Semin Orthod 2012;18:193-201

6 Ackerman MB, Ackerman JL. Smile analysis and design in the digital era. J Clin Orthod 2002;36(4):221-236

7 Singla S, Lehl G. Smile analysis in orthodontics. Indian J Oral Sci 2014;5:49-54

8 Janzen EK. A balanced smile-a most important treatment objective. Am J Orthod 1977;72(4):359-372

9 Ackerman JL, Ackerman MB, Brensinger CM, Landis JR. A morphometric analysis of the posed smile. Clin Orthod Res 1998;1(1):2-11

10 Graber TM, Vanarasdall RL, Vig KW, Orthodontics: Current Principles and Techniques. 4th edition. St. Louis, MO: Mosby Year Book; 2005:46-47

11 Frush JP, Fisher RD. The dynesthetic interpretation of the dentogenic concept. J Prosthet Dent 1958;8:558-581

12 Singh J, Mehrotra P, Kapoor S, Tandon R, Dattada H. Cephalometric soft tissue analysis of individuals with pleasant faces. Journal of Indian Orthodontic Society 2007;41(4):148-161

13 Van der Geld P, Oosterveld P, Kuijpers-Jagtman AM. Age-related changes of the dental aesthetic zone at rest and during spontaneous smiling and speech. Eur J Orthod 2008;30(4):366-373

14 Krishnan V, Daniel ST, Lazar D, Asok A. Characterization of posed smile by using visual analog scale, smile arc, buccal corridor measures, and modified smile index. Am J Orthod Dentofacial Orthop 2008;133(4):515-523

15 Desai S, Upadhyay M, Nanda R. Dynamic smile analysis: changes with age. Am J Orthod Dentofacial Orthop 2009;136:310. el-e10
16 Arnett GW, Bergman RT. Facial keys to orthodontic diagnosis and treatment planning. Part I. Am J Orthod Dentofacial Orthop 1993;103(4):299-312

17 Farkas LG, Katic MJ, Hreczko TA, Deutsch C, Munro IR. Anthropometric proportions in the upper lip-lower lip-chin area of the lower face in young white adults. Am J Orthod 1984;86(1):52-60

18 Wolford LM. Discussion: lip-nasal aesthetics following LeFort osteotomy. Plast Reconstr Surg 1988;81:180-182

19 Scheideman GB, Bell WH, Legan HL, Finn RA, Reisch JS. Cephalometric analysis of dentofacial normals. Am J Orthod Dentofacial Orthop 1980;78(4):404-420

20 Schabel BJ, Franchi L, Baccetti T, McNamara JA, Jr. Subjective vs objective evaluations of smile esthetics. Am J Orthod Dentofacial Orthop 2009;1354) (suppl):S72-S79

21 Chetan P, Tandon P, Singh GK, Nagar A, Prasad V, Chugh VK. Dynamics of a smile in different age groups. Angle Orthod 2013;83(1):90-96

22 Kalha AS, Latif A, Govardhan SN. Soft-tissue cephalometric norms in a South Indian ethnic population. Am J Orthod Dentofacial Orthop 2008;133(6):876-881

23 Sachdeva K, Singla A, Mahajan V, Jaj HS, Negi A. Esthetic and smile characteristics at rest and during smiling. J Indian Orthod Soc 2012;46(1):17-25

24 Dickens ST, Sarver DM, Proffit WR. Changes in frontal soft tissue dimensions of the lower face by age and gender. World J Orthod 2002;3:313-320

25 Sarver DM, Ackerman MB. Dynamic smile visualization and quantification: part 2. Smile analysis and treatment strategies. Am J Orthod Dentofacial Orthop 2003;124(2):116-127

26 Martin AJ, Buschang PH, Boley JC, Taylor RW, McKinney TW. The impact of buccal corridors on smile attractiveness. Eur J Orthod 2007;29(5):530-537

27 Sarver DM, Ackerman MB. Dynamic smile visualization and quantification: part 1. Evolution of the concept and dynamic records for smile capture. Am J Orthod Dentofacial Orthop 2003;124(1):4-12 